\title{
Miosite eosinofílica em bovinos abatidos para consumo humano ${ }^{1}$
}

\author{
Bianca Tessele ${ }^{2}$, Andréia Vielmo ${ }^{3}$, Welden Panziera² ${ }^{2}$ Danilo C. Gomes ${ }^{4}$ \\ e Claudio S.L. Barros ${ }^{5 *}$
}

\begin{abstract}
Tessele B., Vielmo A., Panziera W., Gomes D.C \& Barros C.S.L. 2013. [Eosinophilic myositis in cattle slaughtered for human consumption.] Miosite eosinofílica em bovinos abatidos para consumo humano. Pesquisa Veterinária Brasileira 33(11):1345-1348. Departamento de Patologia, Universidade Federal de Santa Maria, Camobi, Santa Maria, RS 97105-900, Brazil. E-mail: claudioslbarros@uol.com.br

Eosinophilic myositis is a relatively rare inflammatory condition affecting striated muscle of cattle and sheep. It has been usually associated with degenerating cysts of Sarcocystis spp., mainly $S$. cruzi, although this protozoan occurs in the myofibers of almost every cattle without provoking an inflammatory reaction. This paper reports the gross and histopathological findings of eosinophilic myositis in three cattle slaughtered for meat production for human consumption. Grossly lesions were pale yellow, occasionally with a greenish hue, $2-6 \mathrm{~mm}$ spots or strikes in the myocardium of the three cattle and in the masseter muscle of one of them. Microscopically there were granulomatous lesions surrounding a core of dead and degenerating eosinophils and occasional fragment components of Sarcocystis. Immunohistochemistry performed with a policlonal anti-Neospora caninum antibody in the myocardium of one of the cattle marked intact cysts in normal myofibers and intralesional fragments of disrupted cyst amidst areas with strong inflammatory reaction. This latter finding corroborates the opinion of those in favor of Sarcocystis spp. playing a role in the causation of eosinophilic myositis.
\end{abstract}

INDEX TERMS: Parasite-induced lesions in cattle, abattoir survey, eosinophilic myositis, Sarcocystis spp.

RESUMO.- Miosite eosinofílica é uma condição inflamatória relativamente rara que afeta os músculos estriados de bovinos e ovinos. A lesão é usualmente associada a cistos degenerados de Sarcocystis spp., principalmente $S$. cruzi embora esse protozoário ocorra associado às miofibras de praticamente qualquer bovino, sem provocar, na grande maioria das vezes, reação inflamatória. Esse artigo relata os achados macro e microscópicos da miosite eosinofílica em três bovinos abatidos para produção de carne para consumo huma-

\footnotetext{
${ }^{1}$ Recebido em 30 de outubro de 2013.

Aceito para publicação em 18 de novembro de 2013.

Parte da Dissertação de Mestrado do primeiro autor.

${ }^{2}$ Programa de Pós-Graduação em Medicina Veterinária, área de concentração em Patologia Veterinária, Centro de Ciências Rurais (CCR), Universidade Federal de Santa Maria (UFSM), Camobi, Santa Maria, RS 97105- 900, Brasil.

${ }^{3}$ Bolsista PROBIC (Iniciação Científica, FAPERGS), UFSM, Santa Maria, RS.

${ }^{4}$ Setor de Patologia Veterinária, da Faculdade de Veterinária, Universidade Federal do Rio Grande do Sul (UFRGS). Av. Bento Gonçalves 9090, Prédio 42505, Porto Alegre, RS 91540-000, Brasil.

${ }^{5}$ Departamento de Patologia, UFSM, Santa Maria, RS. Pesquisador 1A do CNPq.*Autor para correspondência: claudioslbarros@uol.com.br
}

no. Macroscopicamente, as lesões consistiam de manchas ou linhas amarelo-pálidas, ocasionalmente esverdeadas, de 2-6mm no miocárdio de três bovinos e no músculo masseter de um deles. Microscopicamente, as lesões consistiam de acúmulos inflamatórios granulomatosos circundando um centro constituído por eosinófilos mortos e degenerados e ocasionais fragmentos de Sarcocystis sp. A imuno-histoquímica realizada no miocárdio de um dos bovinos com um anticorpo policlonal anti-Neospora caninum marcou cistos intactos em miofibras normais e fragmentos de cistos em meio a áreas de intensa reação inflamatória. Esse último achado corrobora a opinião dos que apontam Sarcocystis sp. como tendo participação na causa da miosite eosinofílica.

TERMOS DE INDEXAÇÃO: Lesões induzidas por parasitas em bovinos, pesquisa em abatedouro, miosite eosinofílica, Sarcocystis spp.

\section{INTRODUÇÃO}

Miosite eosinofílica é uma condição inflamatória específica dos músculos esquelético e miocárdio, relacionada à degeneração de cistos de Sarcocystis spp. É relativamente rara em bovinos e ovinos, em geral percebida durante a inspeção 
de carne em abatedouros (Van Vleet \& Valentine 2007). Três espécies de Sarcocystis foram descritas em bovinos: $S$. cruzi com o ciclo canino-bovino, $S$. hirsuta com o ciclo felino-bovino, e $S$. hominis com o ciclo humano-bovino (Taylor et al. 2007). Em bovinos, a miosite eosinofílica está associada com S. cruzi (Gajadhar \& Marquardt 1992) e apenas raramente com outras espécies de Sarcocystis (Wouda et al. 2006).

Lesões de miosite eosinofílica contribuem para a condenação de carnes em abatedouros, podendo levar a consideráveis perdas econômicas, chegando à condenação de $5 \%$ das carcaças de bovinos abatidos em matadouros-frigoríficos (Jensen et al. 1986).

0 presente trabalho é parte de uma série de pesquisas realizadas pelo LPV-UFSM sobre lesões encontradas em bovinos abatidos em matadouros-frigoríficos para o consumo humano. Seu objetivo é descrever a ocorrência de miosite eosinofílica no miocárdio e músculo esquelético de bovinos, com a finalidade de orientar os profissionais da inspeção no seu reconhecimento e apresentar dados que corroboram as teorias sobre a etiologia da condição.

\section{MATERIAL E MÉTODOS}

Foram recebidos no Laboratório de Patologia Veterinária (LPV) da Universidade Federal de Santa Maria (UFSM) fragmentos de miocárdio e músculo esquelético de três bovinos de um matadouro-frigorífico sob Inspeção Federal, localizado em Santa Maria, região central do Rio Grande do Sul (RS). Esses três casos são parte de um total de 428 materiais de bovinos recebidos de seis matadouros frigoríficos durante 34 meses pelo LPV/UFSM. Os três bovinos afetados eram oriundos de propriedades distintas de locais diferentes do RS. Dados referentes à idade, raça ou sexo desses bovinos não foram informados. Duas amostras foram recebidas frescas e uma amostra estava fixada em formol a $10 \%$. 0 material foi fotografado, clivado, processado, cortado e corado rotineiramente com hematoxilina e eosina (HE). 0 tecido de um dos bovinos foi submetido ao teste imuno-histoquímico (IHQ) com anticorpo policlonal anti-Neospora caninum.

\section{RESULTADOS}

Macroscopicamente, as lesões musculares consistiam de listras e manchas bem demarcadas, que variavam de 2-6mm de diâmetro, amarelas pálidas, por vezes levemente esverdeadas, localizadas no miocárdio (Fig.1) dos três bovinos e no masseter de um deles. Histologicamente, as lesões musculares consistiam de granulomas, cujo centro era constituído por eosinófilos degenerados e restos de miofibras necróticas. Circundando esse centro necrótico havia uma borda interna de macrófagos epitelioides em paliçada e ocasionalmente células gigantes multinucleadas em meio a infiltrado inflamatório misto constituído por grande número de eosinófilos, linfócitos e plasmócitos (Fig.2). Circundando a lesão e infiltrando as fibras musculares adjacentes havia proliferação de tecido conjuntivo fibroso rico em colágeno. Ocasionalmente, no centro das lesões, exemplares de Sarcocystis degenerados podiam ser observados (Fig.3), enquanto nas áreas adjacentes, podiam ser vistos cistos intactos do protozoário (Fig.4). A IHQ revelou forte marcação positiva dos cistos intactos (Fig.5) e dos fragmentos de Sarcocystis em meio às áreas com intensa reação inflamatória (Fig.6).

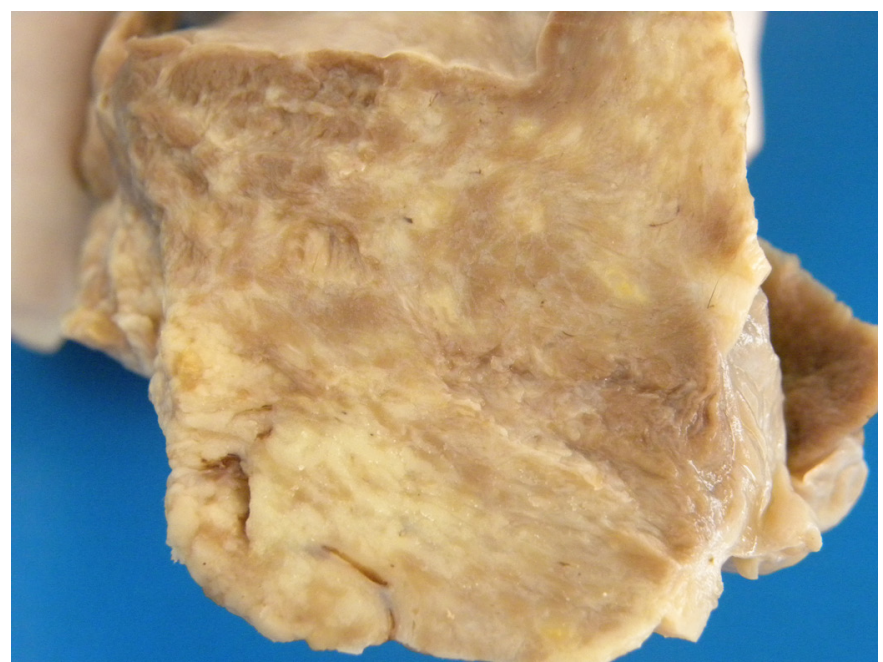

Fig.1. Miocardite em bovino afetado por miosite eosinofílica. As lesões inflamatórias são percebidas como manchas ou linhas pálidas bem demarcadas da musculatura cardíaca normal.

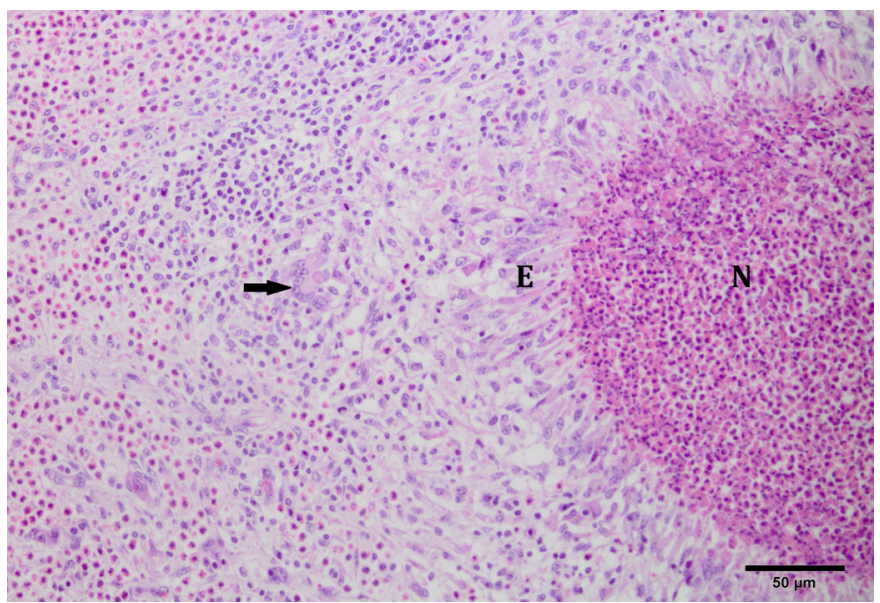

Fig.2. Músculo estriado, lesão histológica característica da miosite eosinofílica em bovino. À esquerda aparece o centro necrótico (N) constituído principalmente de eosinófilos mortos e restos de miofibras. Esse centro necrótico é circundado por macrófagos epitelioides (E) organizados em paliçada com ocasionais células gigantes (seta), circundados por grande número de eosinófilos e moderada quantidade de células mononucleares. HE, obj.40x.

\section{DISCUSSÃO}

Os bovinos se infectam com Sarcocystis ao ingerir esporocistos na comida ou na água; esses esporocistos passam por, pelo menos, três gerações assexuadas. Na primeira, esporozoítos liberados dos esporocistos, invadem a parede intestinal e penetram nos capilares onde permanecem nas células endoteliais realizando dois ciclos esquizogônicos. 0 terceiro ciclo assexuado ocorre em linfócitos circulantes, produzindo merozoítos que penetram nas células musculares. 0 protozoário se encista dando origem a bradizoítos contidos nos cistos, que são os Sarcocystis maduros, estágios infectantes para os carnívoros (Taylor et al. 2007). Por serem intracelulares os cistos de Sarcocystis estão protegidos das defesas imunes do hospedeiro; em razão disso, na vasta proporção dos casos, não ocorre qualquer resposta 


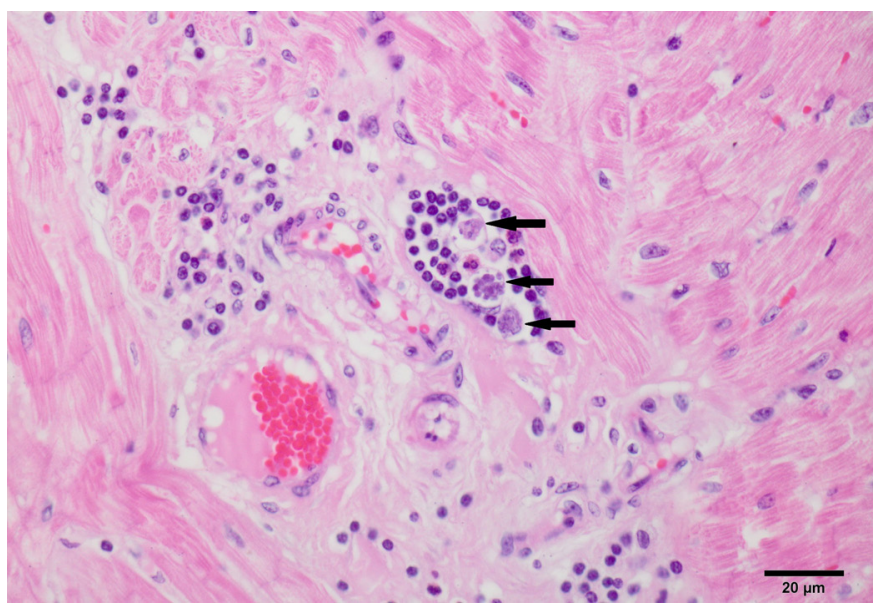

Fig.3. Histopatologia da miocardite em bovino afetado por miosite eosinofílica. Percebem-se restos de Sarcocystis (setas) circundados por reação inflamatória linfocítica. HE, obj.40x.

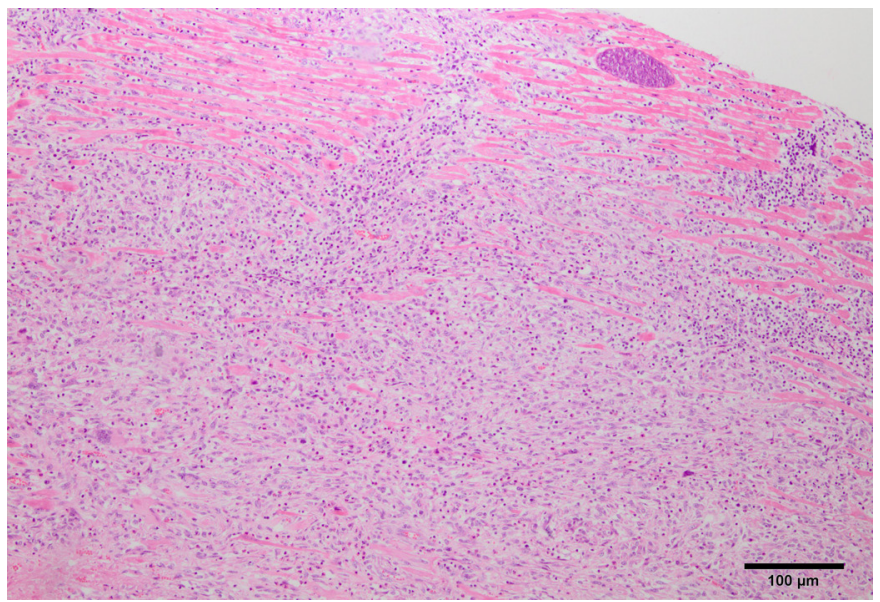

Fig.4. Histopatologia do miocárdio de bovino mostrando cisto parasitário (Sarcocystis sp.) íntegro na periferia da reação inflamatória. HE, obj.40x.

inflamatória associada, e o achado incidental do protozoário em lâminas de músculo estriado é um lugar comum na rotina histopatológica (Valentine \& McGavin 2012). No Rio Grande do Sul acredita-se que a alta prevalência de Sarcocystis em bovinos esteja intimamente ligada ao hábito de se fornecer para a alimentação de cães, vísceras e órgãos de bovinos abatidos em propriedades rurais, ou ao consumo, pelos cães, de carcaças de bovinos mortos no campo por causas diversas (Ford 1986).

A patogênese da miosite eosinofílica não está bem esclarecida e as lesões dessa condição não foram reproduzidas experimentalmente em espécies infectadas com Sarcocystis spp. (Dubey et al. 1989). Especula-se que bovinos com miosite eosinofílica sejam geneticamente predispostos à produção de IgE em resposta ao antígeno de Sarcocystis e que a miosite eosinofílica represente uma resposta anormal (hipersensibilidade do tipo I) à degeneração do parasita (Granstrom et al. 1989). Outros autores afirmam que bovinos infectados pelo protozoário, mas sem miosite, têm níveis séricos de IgE comparáveis aos de bovinos com lesões, sugerindo que a reação inflamatória na miosite eosi-

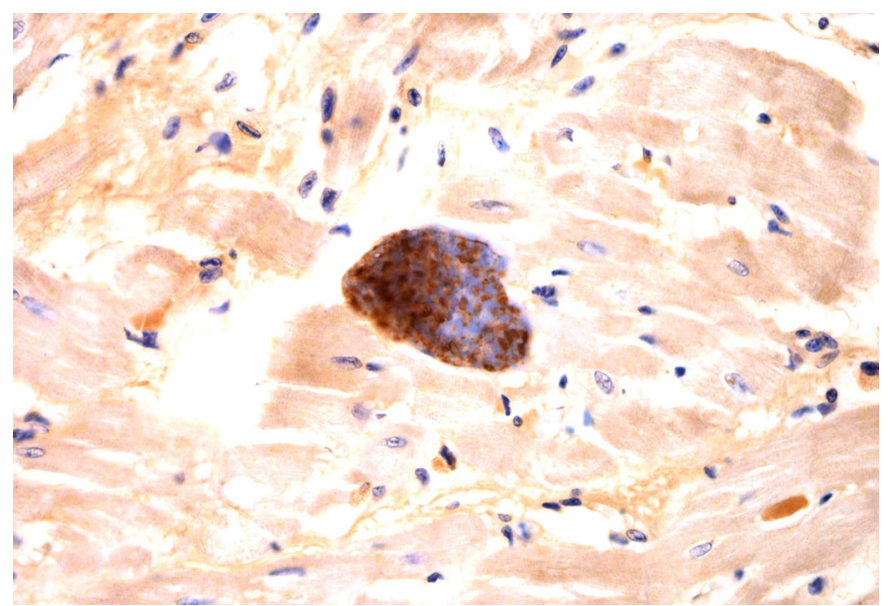

Fig.5. Cisto parasitário íntegro (Sarcocystis $\mathrm{sp}$ ) íntegro na periferia da reação inflamatória na miosite eosinofílica em bovino. $\mathrm{O}$ cisto foi marcado por imuno-histoquímica com anticorpo policlonal anti-Neospora caninum. IHQ, obj.40x.

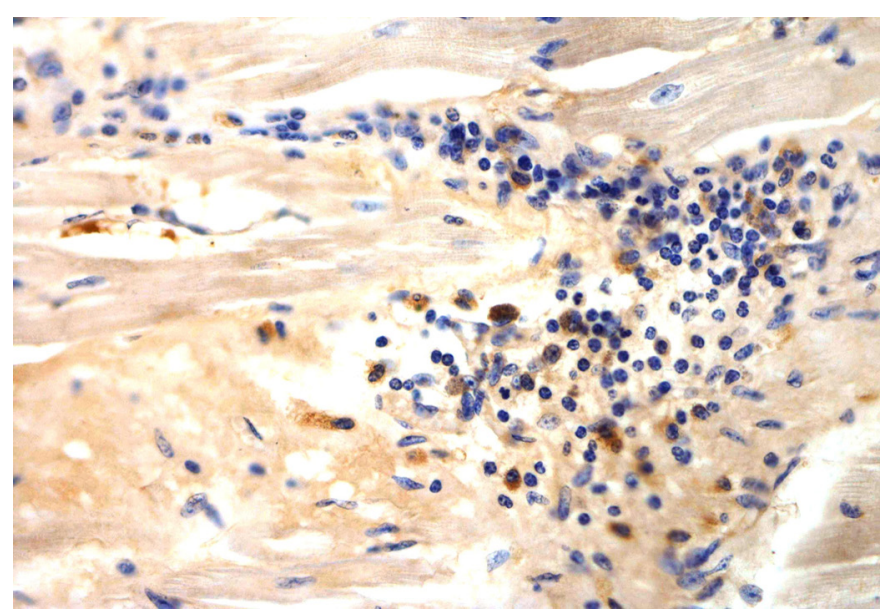

Fig.6. Fragmentos de Sarcocystis em meio a áreas de reação inflamatória na miosite eosinofílica em bovino. Os fragmentos do protozoário foram marcados por imuno-histoquímica com anticorpo policlonal anti-Neospora caninum. IHQ, obj.40x.

nofílica seja estimulada por ruptura do parasita ou trauma nas fibras musculares (Van Vleet \& Valentine 2007), o que levaria à liberação de determinadas toxinas (Jensen et al. 1986). Essa ruptura do cisto pode estar relacionada com um defeito genético no parasita e/ou repetida sensibilização do hospedeiro a uma determinada espécie de Sarcocystis (Gajadhar \& Marquardt 1992).

Sarcocystis são geralmente não patogênicos para os hospedeiros definitivos e algumas espécies são também não patogênicas ou pouco patogênicas para os hospedeiros intermediários. Os sinais clínicos podem ser percebidos durante o segundo ciclo esquizogônico nos vasos sanguíneos (fase aguda), e são caracterizados por febre, anorexia, anemia, emaciação, perda de pelos e, ocasionalmente, morte. Fêmeas prenhes podem abortar. As lesões da miosite eosinofílica representam a fase crônica da doença, na qual, usualmente, os animais afetados são clinicamente normais e as lesões somente são descobertas durante a inspeção de carnes após o abate (Dubey \& Lindsay 2006), de modo semelhante ao que ocorreu nos casos aqui descritos. 
A intensidade e a prevalência dos cistos intactos de Sarcocystis são mais elevadas no coração e esôfago (Gajadhar \& Marquardt 1992). A totalidade das amostras de miocárdio de 305 bovinos de um abatedouro foram positivas para a presença dos cistos do protozoário, seguida de $62,2 \%$ das amostras de esôfago (Ruas et al. 2001). Possivelmente, a maior ocorrência no miocárdio esteja relacionada com a infecção por via digestiva (Dubey et al. 1989). Ao atingir a circulação geral, o protozoário alcança, por via venosa, o coração, alojando-se no miocárdio (Pezzat 1971). Nos três casos aqui relatados as lesões estavam presentes no coração e em um deles havia ainda lesões no masseter, que é considerado o terceiro local mais frequente para a localização dos cistos, perfazendo cerca de $50 \%$ dos casos (Ruas et al. 2001).

Há certa dificuldade no reconhecimento das lesões macroscópicas da miosite eosinofílica na inspeção de carnes em matadouros frigoríficos. Um estudo determinou que dos casos identificados como miosite eosinofílica na linha de inspeção, 25\% foram diagnosticados histologicamente como outras lesões (Smith et al. 1991). Lesões de miosite eosinofílica devem ser diferenciadas de cisticercose (Infante Gil 2000), uma vez que ambas têm localizações semelhantes, pois ambos parasitas têm predileção pela musculatura com bom suprimento sanguíneo (Grist 2008).

Pela histopatologia é possível confirmar o diagnóstico e distinguir um processo ativo de miosite eosinofílica de um achado incidental de Sarcocystis; no primeiro observa-se uma resposta inflamatória associada ao parasita (Dubey \& Lindsay 2006).

Nos casos aqui descritos, o número de Sarcocystis intralesionais foi relativamente pequeno e uma única seção histológica era por vezes insuficiente para revelar a presença do parasita. Outros estudos demonstraram que muitas seções seriadas podem ser necessárias para demonstrar o protozoário em meio às lesões (Gajadhar \& Marquardt 1992). Além disso, em decorrência da destruição provocada pela reação granulomatosa, muitos Sarcocystis são parcial ou completamente destruídos, prejudicando sua visualização. Para auxiliar na identificação do protozoário, a IHQ pode ser realizada utilizando anticorpo policlonal anti- $\mathrm{Ne}$ ospora caninum, já que antígenos de Sarcocystis apresentam reação cruzada com outros protozoários formadores de cistos (Rose 1982), embora muitas vezes com fraca reação positiva (Pescador et al. 2007). Nos casos deste relato em que se utilizou essa técnica, observou-se forte marcação positiva nos cistos intactos e em meio às áreas com intensa reação inflamatória. Reações cruzadas com protozoários pertencentes ao mesmo filo Apicomplexa podem ser observadas ocasionalmente com o uso de anticorpos policlonais anti- $N$. caninum, provavelmente devido à grande variação na fonte de animais utilizados para a produção de anticorpos, no tipo de antígeno e estágio dos parasitas utilizados na imunização dos animais e às variações observadas nos procedimentos imuno-histoquímicos em diferentes laboratórios (Dubey \& Lindsay 1996).

Os diagnósticos do presente relato foram feitos com base na morfologia das alterações histológicas e na confirmação, pela IHQ da associação estreita de Sarcocystis sp. com as lesões. Essas são evidências adicionais da participação desse protozoário na etiologia da miosite eosinofílica.

\section{REFERÊNCIAS}

Dubey J.P. \& Lindsay D.S. 1996. A review of Neospora caninum and neosporosis. Vet. Parasitol. 67:1-59.

Dubey J.P. \& Lindsay D.S. 2006. Neosporosis, toxoplasmosis, and tarcocystosis in ruminants. Vet. Clin. North Am., Food Anim. Pract. 22:645-671.

Dubey J.P., Speer C.A. \& Fayer R. 1989. Sarcocystosis of Animals and Man. CRC Press, Boca Raton, FL.

Ford E.G. 1986. Role of the dog, fox, cat and human as carnivore vectors in the transmission of the Sarcosporidia that affect sheep and meat production. Aust. J. Agric. Res. 37:79-88.

Gajadhar A.A. \& Marquardt W.C. 1992. Ultrastructural and transmission evidence of Sarcocystis cruzi associated with eosinophilic myositis in cattle. Can. J. Vet. Res. 56:41-46.

Granstrom D.E. 1989. Type-I hypersensitivity as a component of eosinophilic myositis (muscular sarcocystosis) in cattle. Am. J. Vet. Res. 50:571-574

Grist A. 2008. Bovine Meat Inspection. $2^{\text {nd }}$ ed. Nottingham University Press, Nottingham. 278p.

Infante Gil J. 2000. Manual de Inspeção Sanitária de Carnes. Vol.2. 2ª ed. Fundação Calouste Gulbenkian, Lisboa. 653p.

Jensen R., Alexander A.F., Dahlgren R.R., Jolley W.R., Marquardt W.C., Flack D.E., Bennett B.W., Cox M.F., Harris C.W., Hoffmann G.A., Troutman R.S., Hoff R.L., Jones R.L., Collins J.K., Hamar D.W. \& Cravans R.L. 1986. Eosinophilic myositis, and muscular sarcocystosis in the carcasses of slaughtered cattle and lambs. Am. J. Vet. Res. 47:587-593.

Pescador C.A., Corbellini L.G., Oliveira E.C., Bandarra P.M., Leal J.S., Pedroso P.M.O. \& Driemeier D. 2007. Aborto ovino associado com infecção por Sarcocystis sp. Pesq. Vet. Bras. 27:393-397.

Pezzat M.M. 1971. Frequencia de Sarcocystis spp. em corazones de bovinos. Veterinária Mexico 2:6-11.

Rose M.E. 1982. Host immune responses, p.329-371. In: Long P.L. (Ed.), The Biology of Coccidia. University Park Press, Baltimore, MD.

Ruas J.L., Cunha C.W. \& Silva S.S. 2001. Prevalência de Sarcocystis spp. (Lankester, 1882) em bovinos clinicamente sadios, da Região Sul do Rio Grande do Sul, Brasil. Revta Bras. Agrociênc. 7:227-230.

Smith H.J., Snowdon K.E. \& Finley G.G. 1991. Eosinophilic Myositis in Canadian cattle. Can. J. Vet. Res. 55:94-95.

Taylor M.A., Coop R.L. \& Wall R.L. 2007. Veterinary Parasitology. $3^{\text {rd }}$ ed. Blacwell, Oxford. 874p.

Valentine B.A. \& McGavin M.D. 2012. Skeletal Muscle. In: Zachary F.J. \& McGavin M.D. (Eds), Pathologic Basis of Veterinary Disease. $5^{\text {th }}$ ed. Elsevier, St Louis. 1344p.

Van Vleet J.F. \& Valentine B.A. 2007. Muscle and tendon, p.185-280. In: Maxie M.G. (Ed.), Jubb, Kennedy \& Palmer's Pathology of Domestic Animals. Vol.2. $5^{\text {th }}$ ed. Academic Press, San Diego.

Wouda W., Snoep J.J. \& Dubey J.P. 2006. Eosinophilic Myositis due to Sarcocystis hominis in a beef cow. J. Comp. Pathol. 135:249-253. 